\title{
Sustainable energy: Is it nuclear or solar for African Countries? Case study on Ghana
}

\author{
Ephraim Bonah Agyekum*, Vladimir Ivanovich Velkin, Ismail Hossain \\ Department of Nuclear and Renewable Energy, Ural Federal University named after the first President of Russia Boris Yeltsin 620002, 19 Mira Street, Ekaterinburg, Russia
}

\section{A R T I C L E I N F O}

\section{Keywords:}

Ghana

Nuclear power plant

Solar power plant

Energy

LCOE

Techno-economic potential

\begin{abstract}
A B S T R A C T
Increasing cost of generating energy through conventional sources coupled with environmental pollution concerns has led to the need to find more sustainable, clean and cheaper sources of energy generation. This paper evaluates two forms of energy: nuclear and solar energy for developing countries with a case study on Ghana. The research found out that Ghana like other several other developing countries have the opportunity to reduce their cost of electricity significantly should any of the under studied technologies be deployed. Obtained LCOE for the $20 \mathrm{MW}$ modelled Solar power plant (SPP) in Navrongo ranges between 5.74 and $9.41 \mathrm{\$} / \mathrm{kWh}$ for real discount and annual interest rates ranging between 1 and 25\%. LCOEs of 125.53-125.55 \$/MWh for discount rates between $3 \%$ and 15\%, respectively were obtained for the $1200 \mathrm{MW}$ nuclear power plant (NPP) expected to be constructed in Ghana. The research concluded with a suggestion that since the NPP project is capital intensive, development of SPP should be given the needed attention in the short to medium term to help build a resilient economy upon which NPP can be considered in the long term. Some financing models were also suggested for the construction of such capital-intensive projects.
\end{abstract}

\section{Introduction}

Availability of energy remains key to the socio-economic development and survival of humans. Traditional sources of energy such as petroleum, natural gas, coal among others have all played key role in human development over the years. However, the use of fossil fuel as a source of energy generation has negative effect on the environment [1]. Emission of carbon dioxide is fast increasing; this has led to an increase in the earth's average surface temperature by $0.76^{\circ}$ Celsius as a result of the continual use of fossil around the world [2]. Leadership of various countries around the globe are left with no option but to explore more sustainable and clean sources of energy to power their country's industrialization and urbanization agenda. The European union in 2007 planned to increase its renewable energy proportion to at least $20 \%$ by 2020 as a result of increasing oil prices [3]. Several other countries are pursuing the renewable energy agenda to help meet their growing energy demand.

Apart from renewable energy, nuclear power is also an option being considered among countries as possible replacement to the traditional sources of energy generation. Several African countries like Ghana, Nigeria, Egypt, Morocco, Kenya, Niger, Tunisia and Uganda among others are all currently considering the addition of nuclear energy to their electricity generation mix [4]. Currently, Ghana has no nuclear power plant (NPP) despite its possible positive impact on the development on the country [5]. Ghana like other African countries is confronted with increasing electricity demand as a result of industrialization and urbanization among others. Demand for electric power in the country is estimated to be appreciating at a rate of $10 \%$ per annum. However, existing power plants are unable to operate at full capacity as a result of fuel supply constraints for the thermal power plants and low rainfall patterns for the hydro dams [6]. As a result of the prolonged power crisis the nation experienced during 2012 to 2016, it was christened "Dumsor" which literally means "off and on", which indicates the seriousness of the challenge. The situation affected the Ghanaian people economically, socially, mentally and academically, it is therefore expedient to diversify the countries sources of energy to prevent such crisis [7].

The quest to provide sustainable energy through renewable and nuclear energy sources have huge economic implications. There are diverse school of thoughts about both technologies, some of these opinions are: renewable energy has the potential to generate both forward and backward linkages within their host economies; it is also the view of some that nuclear power is a potential source of economic development which can be used to conserve political power of nondemocratic countries [8]. However, in as much as both technologies are viable sources of clean energy, the question is, can the current

\footnotetext{
* Corresponding author.

E-mail address: agyekum@urfu.ru (E.B. Agyekum).
} 


\author{
Nomenclature \\ LCOE Levelized cost of energy \\ MW Megawatt \\ NEPIO Nuclear Energy Implementation Organization \\ WAPP West African Power Pool \\ NPP Nuclear Power Plant \\ RE Renewable Energy \\ MoEP Ministry of Energy and Power
}

KfW

ECG

PV

MWh

$\$ / \mathrm{kWh}$

VVER

IRR

GDP
Kreditanstalt für Wiederaufbau Bankengruppe

Electricity Company of Ghana

Photovoltaic

Megawatt hour

cent per kilowatt hour

Water-Water Energetic Reactor

Internal Rate of Return

Gross Domestic Product economic condition in African countries support the development of nuclear energy? This paper evaluates the techno-economic potential of both nuclear and solar energy for a possible integration into the Ghanaian and other developing countries' energy generation mix. It also evaluates the continent's economic readiness relative to nuclear energy development in terms of gross domestic product (GDP). The LCOE metric was used to analyze the economic viability of both projects and the impact of such investment on the economy of African countries using Ghana's economic conditions as a case study. The objective of this paper is to provide the techno-economic potentials of these two different technologies in the context of developing countries using their economic indicators to serve as a reference material for both policy and decision makers. The research has four main sections, section 1 covers the introduction and the current electricity situation in Ghana as well as the history of the NPP project in Ghana, section 2 also covers the methodology and parameters used for the analysis section 3 presents the results for the analysis and possible funding options, whiles section 4 covers the conclusion and recommendations.

\section{Usage and composition of electric power in Ghana}

Ghana has over $83.24 \%$ (50\% rural and $91 \%$ urban) of its population connected to electrical power, second to South Africa in the subregion [9]. However, over the last two decades, supply of electric power has been erratic as a result of either lack of installed capacity or inability of government to purchase fuel to run the installed thermal power plants as a result of high debt in the sector or both. The nation has experienced at least three power crises since the year 2000, first in the year 2002, then 2006-2007 and most recently in 2012-2016. The situation has been stabilized since 2017 by the purchase of some emergency power plants by the government of Ghana. The government has envisioned to add $10 \%$ renewables to the energy mix by 2020 [10]. As a result of that, the government of Ghana has made significant effort towards the integration of solar power into the country's generation mix. The country's largest solar power plant (20 MW) was commissioned and connected to grid in April 2016 [11]. Ghana's electricity composition is mainly thermal, hydro and an infinitesimal percentage from solar. Fig. 1 shows the country's total installed capacity in terms of percentage.

\section{Roadmap for Ghana's nuclear power project}

The idea to integrate nuclear power into Ghana's electricity generation mix dates back to 1961 when the country's first president Dr. Kwame Nkrumah envisioned to do so, however, the idea went into hibernation after his exit from power. The idea was revived by the government of Ghana in 2007 due to the country's recurring power crisis. A Nuclear Power Committee was inaugurated in May 2007 to assess the feasibility of adding nuclear energy to the energy mix and also develop a road map for its development in the country. The committee after their assessment, recommended that nuclear energy could play a key role in the country's energy mix in the future. A road map for the country's first 400 MW scheduled to be constructed by 2018 was launched at the time. It also recommended the formation of the
Presidential Commission on Nuclear Power Development which will act as the Nuclear Energy Implementation Organization (NEPIO) [13].

Ghana was awarded technical corporation project (TCP) GHA/0/ 011 - Establishment of infrastructure for Nuclear Electricity Generation in Ghana under the auspices of the Ghana Atomic Energy Commission. A framework for the development of nuclear power was expected to be developed after a successful execution of the IAEA's TCP GHA/0/011. Seven working groups were formed in April 2011 to assist in the planning of the project. NEPIO was tasked to coordinate the activities of all stakeholders engaged in the planning of the NPP project. Issues such as the following were expected to be addressed by the seven working groups [14]:

- Site selection: the group was expected to assess the potential sites, evaluate the chosen sites for characterization and final determination. They were also required to evaluate the national grid and its interconnection with the West African Power Pool (WAPP) and also strategize for the operation of nuclear power for the country and WAPP.

- Techno-economic Evaluation, Financing and Procurement: they were expected to review the role of nuclear energy in the country's future electricity expansion and perform a complete techno-economic assessment in that regard. A strategy for funding the project as well as handling of the spent fuel and its final disposal, management of the waste and decommissioning of the NPP were all expected to be assessed by the working group.

- Human Resource Development: human resource is key in the operation of an NPP and the group was expected to undertake assessment of the human resource required at all stages of the program.

- Assessment of Technology: the specific technology to be used in the nuclear power project was also their responsibility, they were also required to draw a plan for nuclear waste management.

- Legal and Regulatory Frame Work: all legal and regulatory issues relative to the nuclear power project was expected to be addressed by the group. A bill for the nuclear power project has been drafted, the bill proposed the creation of a Nuclear Regulatory Authority to oversee the licensing of NPP's and other related facilities. The Bill has since been submitted to Cabinet for approval.

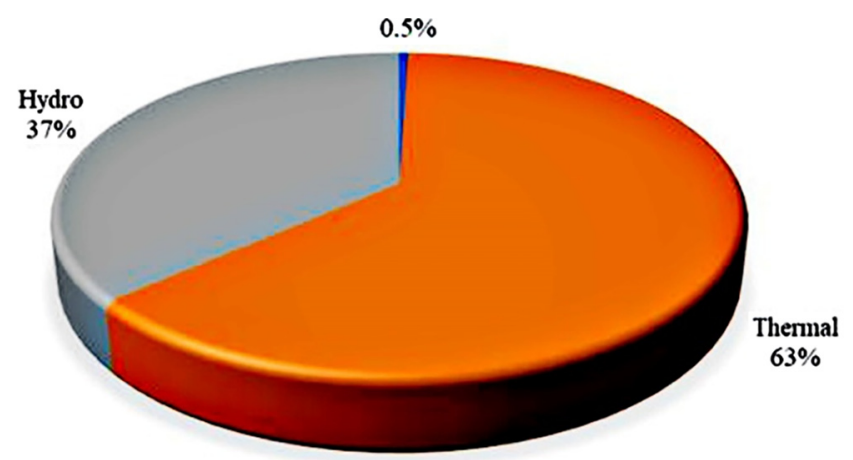

Fig. 1. Composition of Ghana's installed electricity generation capacity [12]. 
- Stakeholder Participation: they were expected to develop a communication strategy for the creation of awareness among the Ghanaian people.

- Management of the Nuclear Power Project: this group were expected to also develop a framework for the project including activities and time scales. It is expected of them to also develop the best strategy or contract for securing an NPP.

A roadmap has since been developed for the construction and commissioning of Ghana's first NPP by 2030. The roadmap is illustrated in Fig. 2.

\section{Renewable energy potential in Ghana}

Ghana just like other African countries is endowed with lot of renewable energy (RE) resources (solar, wind, mini to large hydro, wave energy, modern biomass among others) which can be explored for electricity generation [12]. The government as part of its policy to increase the use of renewable energy, passed the renewable energy Act in 2011 [15]. For a country to successfully integrate renewable energy into its electricity generation mix, it ought to have a detailed knowledge of its renewable energy resources and their capacity to deliver the required energy for which they have been built for or expected to be built for. This section reviews the solar energy potential of the country.

Use of solar energy and its potential in Ghana

Ghana is located in the tropics where solar radiation is abundant, the country receives an average solar radiation of $4.0-6.5 \mathrm{kWh} / \mathrm{m}^{2} /$ day and a sunshine duration of 1800-3000 h per year. The northern part of the country receives the highest solar radiation. Solar energy potential in the country is estimated to be about 35 EJ (Exajoules) [16].

The state has embarked on a policy to increase the use of solar energy in the rural areas, the Ministry of Energy and Power (MoEP) shared close to 15,000 solar systems in rural Ghana which is estimated to be about 3.2 MW of installed capacity. This was done by the Ghana Energy and Development Project which was financed by development partners. A 2.5 MW SPP was also commissioned in 2013 by the Volta River Authority (VRA), which is connected to the national grid at Navrongo, as part of VRA's agenda to increase renewable energy [17]. VRA also plans to build a 12 MW capacity SPP in the Upper West at Lawra and Kaleo with funding from Kreditanstalt für Wiederaufbau Bankengruppe (KfW), a German government-owned development bank. They are also negotiating for a 57 ha land in the Upper East region at Bongo in their quest to adding $100 \mathrm{MW}$ solar power to the national grid
Table 1

Summary of solar irradiation for some cities in Ghana [18].

\begin{tabular}{llll}
\hline Synoptic Station & Ground, $\mathrm{kWh} / \mathrm{m}^{2} / \mathrm{d}$ & Satellite, $\mathrm{kWh} / \mathrm{m}^{2} / \mathrm{d}$ & $\%$ Error \\
\hline Accra & 5.060 & 5.180 & -2.3 \\
Kumasi & 4.633 & 5.155 & -11.3 \\
Navrongo & 5.505 & 5.765 & -4.7 \\
Abetifi & 5.150 & 5.192 & -0.8 \\
Wa & 5.520 & 5.729 & -3.7 \\
Wenchi & 5.020 & 5.093 & -1.5 \\
Akuse & 4.814 & 5.580 & -15.9 \\
Ho & 5.122 & 5.223 & -2.0 \\
Kete Krachi & 5.280 & 5.345 & -1.3 \\
Yendi & 5.370 & 5.632 & -4.8 \\
Takoradi & 5.011 & 5.200 & -3.8 \\
Bole & 5.323 & 5.570 & -4.6 \\
\hline
\end{tabular}

in the next six years. Some international and national developers have articulated their interest in developing a utility scale SPP including Blue Energy who have expressed their intention to build a $155 \mathrm{MW}$ plant in the Western Region [17]. Table 1 shows the summary of Solar irradiation in $\mathrm{kWh} / \mathrm{m}^{2} /$ day across some cities and towns in the country. Fig. 3 shows the solar radiation map of Ghana. Table 2 shows the financial paramters used for the modelling of the SPP.

\section{Methodology}

Case study 1 - Solar energy analysis

The modelling of the SPP was performed using the System Advisor Model (SAM) software, version 2018.11.11. SAM is a program developed by the National Renewable Energy Laboratory (NREL) in the United States of America. It calculates performance and financial metrics for different renewable energy technologies [20]. The SAM software uses data from NASA to perform its analysis. The software was used to model a PV power plant for Navrongo in the Upper East of Ghana located on latitude $10.90^{\circ} \mathrm{N}$ and longitude $-1.10^{\circ} \mathrm{E}$. One characteristic of the selected site is the availability of vast land enough for the execution of large-scale SPP, the region has a total land area of $8,842 \mathrm{~km}^{2}$ representing $3.7 \%$ of Ghana's total land area [21].

The levelized cost of energy (LCOE) is a criterion used in comparing two different technologies of different capacities, capital cost, project size and lifetime. The LCOE is an economic assessment of the entire cost to construct and operate a power plant during its lifetime divided by the entire electricity output of the plant during the project's lifetime. The

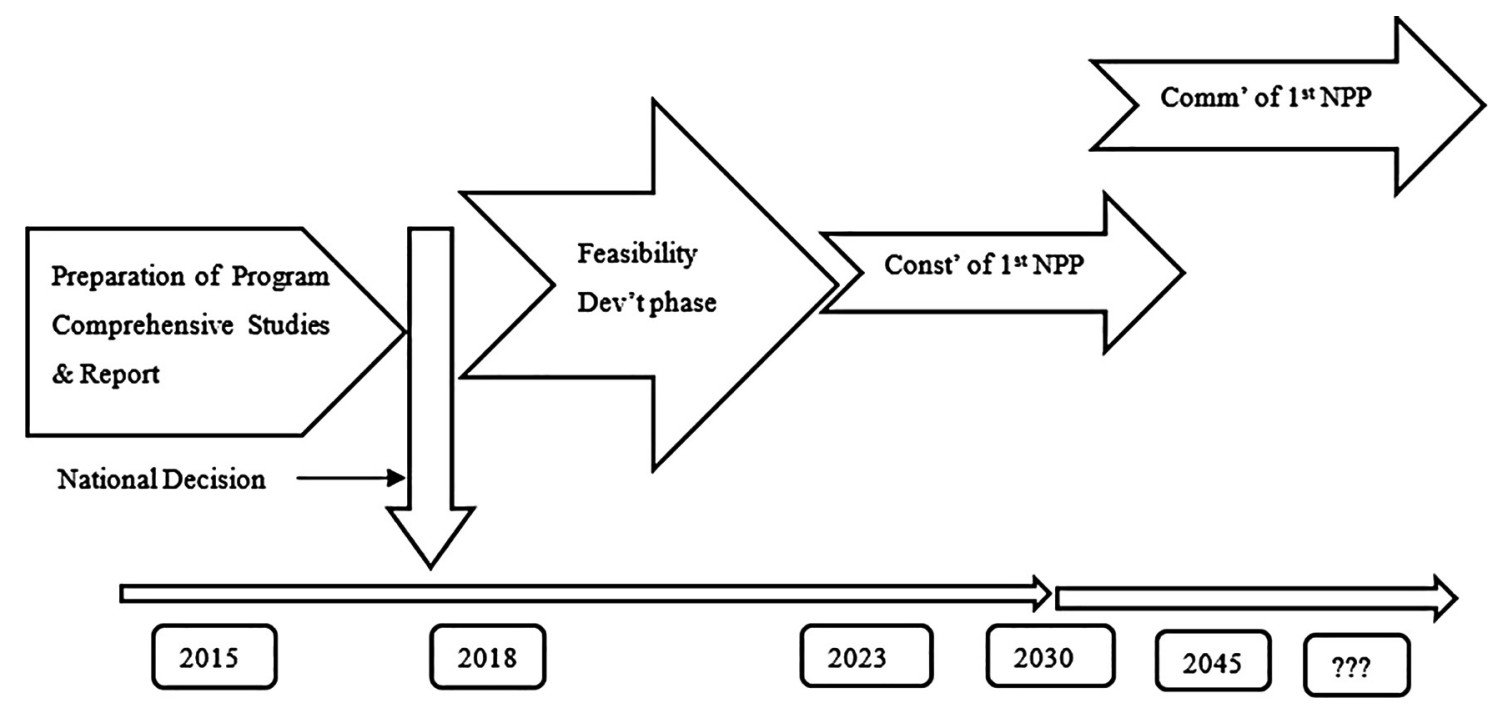

Fig. 2. Road map for Ghana's Nuclear Power Project [14]. 


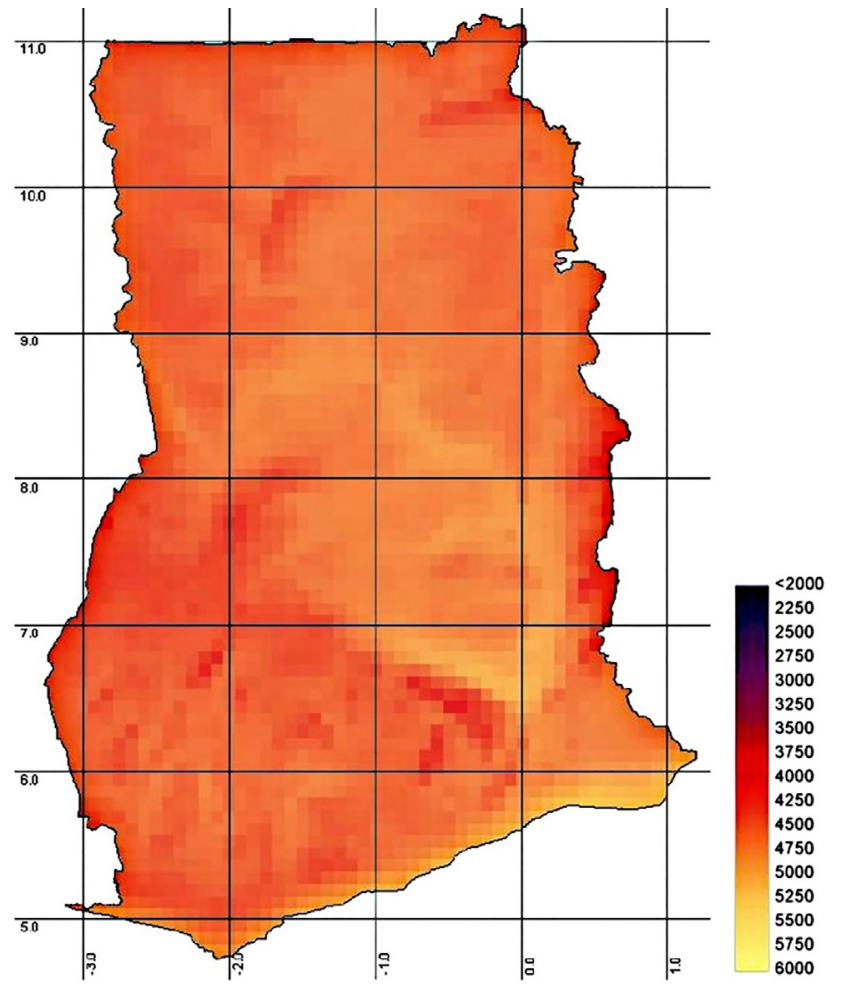

Fig. 3. Annual average solar radiation $\mathrm{Wh} / \mathrm{m}^{2} /$ day in Ghana (3-years average) $[15,19]$.

Table 2

Financial Parameters for the modeling of the solar PV.

\begin{tabular}{lll}
\hline Main Financial Parameters & Data & References \\
\hline $\begin{array}{l}\text { Internal Rate of Return (IRR) } \\
\quad \text { target }\end{array}$ & $11 \%$ & Info from experts \\
$\begin{array}{l}\text { Inflation rate } \\
\text { Real discount rate }\end{array}$ & $2.2 \%$ per year & {$[24]$} \\
Nominal discount rate & $10 \%$ & {$[25]$} \\
& $18.6 \%$ per year & Calculated by \\
Project Term Debt & & software \\
Debt fraction & $70 \%$ of the total & Info from experts \\
& capital cost & \\
Annual interest rate & $5 \%$ & {$[26]$} \\
Weighted Average Cost of Capital & $5.34 \%$ & Calculated by \\
$\quad$ (WACC) & & software \\
Tax and Insurance Rates & $12 \%$ & {$[27]$} \\
Sales tax & $25 \%$ & {$[28]$} \\
National income tax rate & $0.5 \%$ of the installed & {$[29]$} \\
Annual Insurance rate & cost & \\
& &
\end{tabular}

Net Present Value (NPV) is also key to the economic viability of a project. A positive NPV indicates an economically viable project whiles a negative NPV indicates otherwise. The LCOE and the NPV can be calculated using Eqs. (1) and (2) respectively [22].

$L C O E=\frac{\sum_{t}^{T}\left[\frac{\text { Investment }+ \text { OPEX }+ \text { Decommisioning }+ \text { Fuelcost }}{(1+r)^{t}}\right]}{\sum_{t}^{T} \frac{\text { Electricity }}{(1+r)^{t}}}$

where, $r$ is the discount rate, $T$ is the expected lifetime of the plant.

The SAM software estimates both the nominal and real LCOE, the real LCOE is an inflation adjusted value whiles the nominal LCOE is the current dollar value. The study used the real LCOE since it is the most appropriate for a long-term assessment, the nominal value is more appropriate for short-term analysis. The real LCOE takes inflation rate into account, it removes the inflation effect associated with cost of fuel, O\&

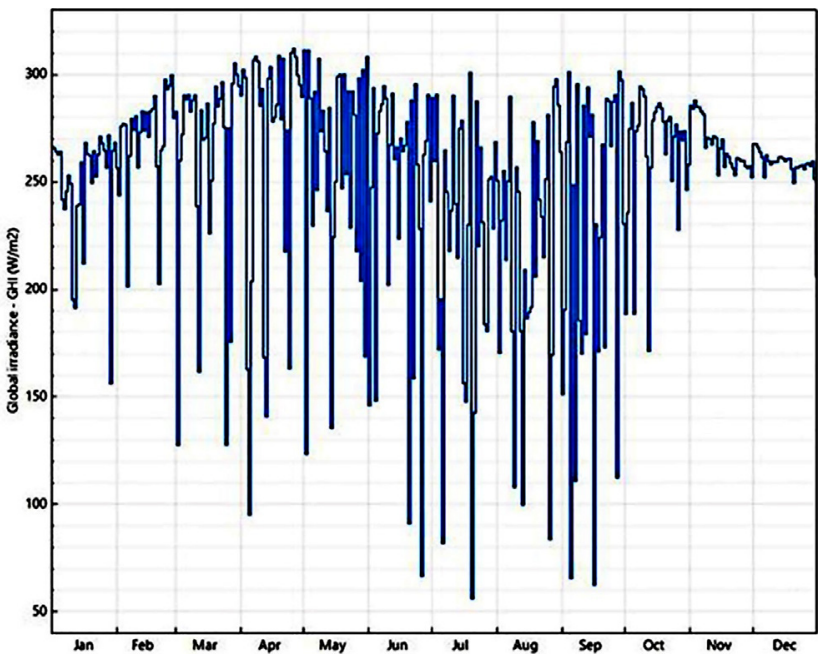

Fig. 4. Global Horizontal irradiance of Navrongo from SAM software.

$\mathrm{M}$ among others. It is a very important metric for assessing the economic viability of a project [23].

$N P V=\sum_{i} V_{o}=\sum_{i} \frac{V_{i}}{(1+d)^{i}}$

where, $V_{o}$ is the present value of a future transaction $V_{i}$ which may be either negative or positive.

\section{Solar irradiation}

One of the key factors to be considered before the installation of an SPP is the availability and the intensity of solar radiation, it is the source of input which is converted into electricity by the modules. The SAM software modelled the solar resource available at the selected area and the solar global horizontal irradiance (GHI) is as indicated in Fig. 4. The rainfall season at the selected area peaks in the months of June, July and August, and this is what accounts for the fall in solar irradiance during those periods as can be seen in Fig. 4 .

A conservative discount rate between $10 \%$ and $12 \%$ is adopted by the International Energy Agency for the construction of PV systems [25]. Annual insurance premiums for PV power plants usually ranges between $0.25 \%$ and $0.5 \%$ of the total cost of installation for the project depending on the geographic location of the installation [29].

A mono-crystalline panel type was used in the modelling as a result of its high efficiency. A mono-crystalline was selected for the following reasons: it has high efficiency, highly durable, needs a relatively less space, performs well in warm weather even though its performance suffers as temperature lowers [30]. The SunPower SPR-E-19-310-COM module was used for the analysis. Table 3 shows the technical parameters used for the modelling in the SAM software. Fig. 5 illustrates the characteristics of the used module. The SMA America: SC750CP-US (with ABB EcoDry ultra transformer) inverter was selected for this analysis.

Table 3

Technical parameters.

\begin{tabular}{lll}
\hline Description & Unit & Data \\
\hline Installed capacity & MW & 20 \\
Number of Modules & & 64,488 \\
Module material & & Mono-C-Si \\
Total land area & acres & 86.6 \\
Number of invertors & & 22 \\
Total Module Area & $\mathrm{m}^{2}$ & $105,179.9$ \\
Degradation rate & $\%$ & $0.5 \%$ \\
Analysis Period & years & 25 \\
\hline
\end{tabular}




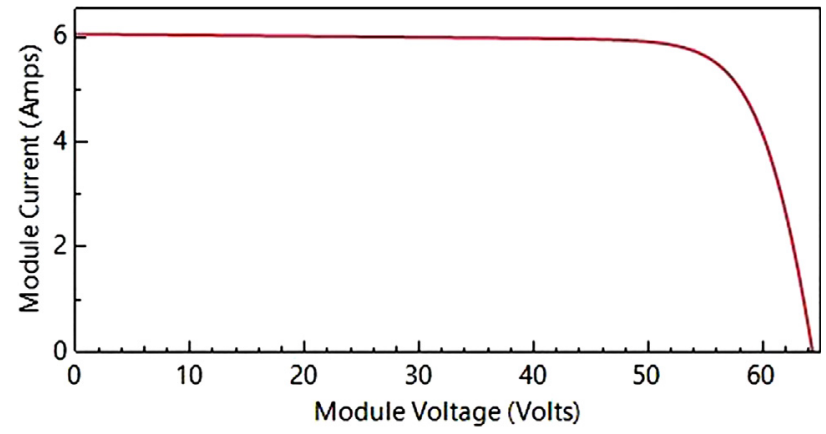

Fig. 5. SunPower SPR-E-19-310-COM module characteristics.

Jordan and Kurtz [31] reported that nearly $78 \%$ of all 2000 studied power plants had degradation rates below $1 \%$. They found a median of $0.5 \%$ degradation rate for all PV technologies, hence the reason for the selected degradation rate.

\section{Case study 2 - Nuclear power plant (NPP)}

This section presents data on the $1200 \mathrm{MW}$ nuclear power plant the Government of Ghana and ROSATOM intend to construct. The government of Ghana through the VRA, Bui Power Authority (BPA) and the Ghana Atomic Energy Commission intend to construct a $1200 \mathrm{MW}$ Russian VVER by 2030 [32]. NPPs have a huge capital cost for the construction of the first plant in a country, however, the economies of scale development of supply chain drive down the cost for any subsequent additional power plant [33]. The operational, maintenance and fuel cost are relatively small components of the entire cost [34]. Construction of an NPP takes a longtime to complete. This does not include the long period needed for preparations to get the license for such a facility. The overnight cost and interest during construction period can be affected by the period of construction [35].

Existing NPPs around the globe have a lifetime of 40 years but can be prolonged to 60 years at maximum [36]. Construction of a $1200 \mathrm{MW}$ VVER nuclear power plant is expected to cost between 6 and 9 billion dollars excluding VAT [37]. A 60-year lifespan for the project was used for the analysis. This work also assumes a cost of $\$ 7$ billion for the construction of Ghana's NPP excluding VAT and $\$ 7.88$ billion including a $12.5 \%$ VAT [38], whiles, $24 \%$ of the total cost is considered for the OPEX cost with an $11 \%$ discount rate and an assumed ratio of investment cost of $60 \%$ as in Ref $[39,40]$. The cost of decommissioning is taken to be $15 \%$ of the investment cost [41]. Also, cost of fuel cycle is assumed to be $16 \%$ of the total cost. In the case of the Turkish Akkuyu VVER NPP, a total of $\$ 3.0 / \mathrm{MWh}$ is earmarked for the financing of the management of the waste generated and decommissioning activities [42]. We assumed a 4-year preparatory time and a 7-year construction period for the plant to produce its first power in the 12th year of the project. We assumed a capacity factor of $90 \%$ with an operating time of $7800 \mathrm{~h}$, which means the power plant is expected to generate about 7.9 TWh of electricity per year.

\section{Results and discussions}

This section evaluates the techno-economic potentials of the two different power plants and the ability of developing economies to integrate them into their electricity generation mix. A sensitivity analysis was also conducted to ascertain the effect of some financial parameters on the cost-effectiveness of such projects.

\section{LCOE evaluation for NPP}

From literatures, the construction time of an NPP between the first pouring of concrete and commissioning can take as long as 19 years as in the case of Brazil, 16 years for that of Mexico and 8.5 years in the case of South Africa among others [43]. This is exclusive of the longer period needed for preparation to meet the IAEA requirements necessary for licensing and construction. The construction period is an important issue that must be factored during a comparative analysis on the economic competitiveness of nuclear and solar energy. The LCOE for a VVER-1200 model was evaluated based on the information provided above using Eq. (1). An LCOE of 125.53 \$/MWh was obtained for discount of $11 \%$. The obtained LCOE falls within Lazard's estimated LCOEs in 2017 which ranges between $\$ 112$ and $\$ 183$ per MWh at a discount rate of $8 \%$ [44].

The capital cost of an NPP is key to the total cost of electricity, the complex (high-technological) nature of building an NPP sometimes contributes to delays in construction period, and under such situations, the project is subjected to changes in commodity prices along the construction periods which could influence the overall cost during the construction. The overnight cost of an NPP in 2000 was $\$ 1729 / \mathrm{kW}$, it remained relatively static for 6 years and increased to $\$ 1802 / \mathrm{kW}$. It rose to $\$ 2874 / \mathrm{kW}$ in 2009 and $\$ 4567 / \mathrm{kW}$ by 2011 [45]. Since then, the

Table 4

Lead-times for the various NPP projects around the world [43].

\begin{tabular}{|c|c|c|c|c|c|c|c|c|c|c|c|c|c|c|}
\hline \multirow[t]{2}{*}{ Country } & \multicolumn{2}{|c|}{ 1976-1980 } & \multicolumn{2}{|c|}{ 1981-1985 } & \multicolumn{2}{|c|}{ 1986-1990 } & \multicolumn{2}{|c|}{ 1991-1995 } & \multicolumn{2}{|c|}{ 1996-2000 } & \multicolumn{2}{|c|}{ 2001-2005 } & \multicolumn{2}{|c|}{ 2006-2010 } \\
\hline & No. & Mths & No. & Mths & No. & Mths & No. & Mths & No. & Mths & No. & Mths & No. & Mths \\
\hline Argentina & & & 1 & 109 & & & & & & & & & & \\
\hline Armenia & 2 & 73 & & & & & & & & & & & & \\
\hline Belgium & & & 4 & 80 & & & & & & & & & & \\
\hline Brazil & & & 1 & 132 & & & & & 1 & 176 & & & & \\
\hline Bulgaria & 1 & 87 & 1 & 104 & 1 & 89 & 1 & 113 & & & & & & \\
\hline Canada & 4 & 69 & 7 & 98 & 5 & 101 & 2 & 97 & & & & & & \\
\hline China & & & & & & & 3 & 73 & & & 6 & 60 & 2 & 80 \\
\hline Czech Rep & & & 1 & 74 & 3 & 93 & & & 1 & 167 & 1 & 191 & & \\
\hline Finland & 4 & 63 & & & & & & & & & & & & \\
\hline France & 13 & 66 & 24 & 68 & 15 & 86 & 3 & 93 & 4 & 124 & & & & \\
\hline Hungary & & & 2 & 112 & 90 & & & & & & & & & \\
\hline India & 1 & 152 & 2 & 154 & 1 & 152 & 3 & 120 & 4 & 122 & 1 & 64 & 3 & 74 \\
\hline Italy & 1 & 101 & & & & & & & & & & & & \\
\hline Japan & 11 & 61 & 10 & 46 & 8 & 49 & 10 & 46 & 3 & 42 & 4 & 47 & 1 & 53 \\
\hline Pakistan & & & & & & & & & 1 & 83 & & & & \\
\hline Russia & 6 & 74 & 9 & 73 & 4 & 72 & 1 & 109 & & & 2 & 233 & & \\
\hline South Africa & & & 2 & 102 & & & & & & & & & & \\
\hline Spain & & & 5 & 112 & 2 & 96 & & & & & & & & \\
\hline Sweden & 3 & 85 & 4 & 74 & & & & & & & & & & \\
\hline Taiwan & 2 & 64 & 4 & 72 & & & & & & & & & & \\
\hline
\end{tabular}


projected costs have stabilized around $\$ 4646 / \mathrm{kW}$. The local conditions in a particular country affects the capital cost. According to the IEA, the capital cost for NPP in the OECD regions ranges from $\$ 2021 / \mathrm{kW}$ in South Korea to about $\$ 6215 / \mathrm{kW}$ in Hungary. It costs about $\$ 1807 / \mathrm{kW}$ and $\$ 2615 / \mathrm{kW}$ in China for different nuclear projects. The differences could be associated to labor and commodity costs which are jurisdictional and the construction duration [45].

Table 4 shows a historical overview of NPPs connected to grid in a five-year period together with the median construction time period for the reactors in months excluding suspended periods during construction. Russia have after 2010 operationalized several nuclear reactors some of which started as far back as 1986 in the case of the Kalinin 4 which was commercialized in 2012. The Rostov 4 reactor which was commissioned in 2018 was also started in 2010 [46].

\section{LCOE for solar power plant (SPP)}

This section also presents an assessment on the current competitiveness relative to the cost of solar PV using the LCOE concept as widely used in Ref $[44,47,48]$. From Table 5 the real LCOE for a discount rate of $10 \%$ is $7 \mathrm{\phi} / \mathrm{kWh}$ for the modelled $20 \mathrm{MW}$ SPP. The obtained LCOE is less than the current average end-user tariff of 15-19 $\$ / \mathrm{kWh}$ in Ghana [12]. This means, developing solar power on a large scale has the potential to reduce the cost of electricity for both industrial and residential users. According to the Energy Commission's 2018 [12] report, current cost of electricity in Ghana is amongst the highest in the sub-region. The modelled power plant is expected to generate about $32,430,662 \mathrm{kWh}$ of electricity in the first year. According to DOE, the average price of utility-scale solar is now below $\$ 1$ per watt and went under 6 cents per kilowatt-hour in September 2017 which results in a unit capital cost of $\$ 1000 / \mathrm{kW}$ [49]. Fig. 6 shows the monthly energy production for the simulation, the month of January and December recorded the highest energy production due to the high solar radiation within that period. June, July, August and September as expected recorded the least energy production due to the rainy nature of that period. Fig. 7 shows the cash flow from the project after tax during the 25-year period.

The obtained LCOE is compared with existing LCOEs of power plants around the world to ascertain the competitiveness of the modelled power plant. Figures from Table 6 indicates that the obtained LCOE falls within the estimated cost around the world which validates the selected parameters used for the modelling.

\section{Sensitivity analysis for SPP and NPP}

A sensitivity analysis was done to investigate the impact of some financial parameters such as the annual interest, real discount and national tax rates on the economic viability of the SPP project. As indicated in Fig. 8, the LCOE for the SPP depends significantly on the real discount rate and the annual interest rate, however, the national or federal tax rate have a relatively insignificant effect. The real discount rate also has a substantial impact on the NPV, as illustrated in Fig. 9, the viability of a solar power plant at the selected location have a negative outlook with a real discount rate above $10 \%$.

As indicated in Fig. 10, the effect of the discount rate is minimal on the LCOE of the NPP, the LCOE largely stayed in a region of 125 \$/MWh. Cost of land among other factors could however have a significant impact on the LCOE.

\section{Comparative analysis}

Ghana's Gross Domestic Product (GDP) as at April 2019 was US $\$ 68.26$ billion. Construction of NPPs comes with huge capital cost. This is a challenge encountered regardless of geographical location [51]. Countries with NPPs are countries with relatively stronger economic fundamentals. Though, GDP alone is not a measure of how healthy an economy is, it is a key indicator of how ready a nation is, relative to embarking on huge projects which are capital intensive such as the construction of an NPP. The Ghanaian project may get international assistance or sponsorship from the Russian State Atomic Energy Corporation (ROSATOM) or other countries such as France and China who have expressed an interest to help the country to construct an NPP but as to whether it will be a total funding or a percentage of the total cost, that is yet to be determined. In a situation where the government of Ghana is required to provide a percentage of the total cost needed for the construction it is likely to severely affect the country's budget. Ghana has had an average debt to GDP ratio of $57.68 \%$ from 1990 to 2017 [52]. The IMF have projected that the country's debt to GDP ratio could hit $62 \%$ by close of 2019 as indicated in Table 8 , this gives the government little fiscal space to solely finance the cost of a nuclear power plant at a cost of 7.88 billion USD since it has limited space to borrow. A high debt to GDP ratio also increases the risks for such huge investment which scare international investors from investing in the country.

Ghana's current installed capacity is more than needed according to the Energy Commission's report in 2018 [12]. This clearly indicates that the country currently consumes below what it is capable of producing. However, authorities envision a scenario of positioning the country as a net exporter of electricity in the sub-region. The construction period to build an NPP up to the time it is operationalized is crucial for its competitiveness in the electricity market. The construction period can be lessened if there exist a collaborative atmosphere between government, regulators, constructors and utilities.

Whiles the construction of NPPs come with huge cost on the budgets of nations that build them, solar energy and renewables come at a relatively low cost. The VRA commissioned a $2.5 \mathrm{MW}$ solar PV plant at Navrongo at the cost of 8 million USD [12]. The ministry of energy has also targeted some potential renewable energy sources across the country with the estimated cost required for construction as shown in Table 7. On the face value, the country needs between 100 and 150 million USD to construct a $50 \mathrm{MW}$ solar power plant and per earlier analysis the least amount of money needed to construct a nuclear power plant is in the region of 7 billion USD. This means that the least amount of money required to construct NPP with a $1200 \mathrm{MW}$ in Ghana can construct about $2333 \mathrm{MW}$ of power from solar power using the Energy Commission's \$150 million for a 50 MW SPP.

\section{Apportionment of cost risks relative to NPP}

Financing of NPPs just like other huge capital-intensive power projects have changed in the past decade. Interested investors have capitalized on global capital markets to vary the sources of investments

Table 5

Financial results for the modelled SPP.

\begin{tabular}{lll}
\hline Metric & Units & Value \\
\hline Annual Energy (year 1) & $\mathrm{kWh}$ & $32,430,662$ \\
Capacity factor (year 1) & $\%$ & 18 \\
Energy yield (year 1) & $\mathrm{kWh} / \mathrm{kW}$ & 1621 \\
Performance ratio (year 1) & & 0.75 \\
PPA Price (year 1) & $\$ / \mathrm{kWh}$ & 7.84 \\
PPA price escalation & $\% / \mathrm{year}$ & 1.00 \\
Levelized PPA Price (nominal) & $\$ / \mathrm{kWh}$ & 8.37 \\
Levelized PPA Price (real) & $\$ / \mathrm{kWh}$ & 7.06 \\
Levelized COE (nominal) & $\$ / \mathrm{kWh}$ & 8.31 \\
Levelized COE (real) & $\$ / \mathrm{kWh}$ & 7.00 \\
Net Present Value & $\$$ & 158,864 \\
IRR, & $\%$ & 11 \\
IRR at end of project, & $\%$ & 12.91 \\
Year IRR is Achieved, & year & 20 \\
Net capital cost & $\$$ & $23,291,148$ \\
Equity & $\$$ & $10,541,747$ \\
Size of debt & $\$$ & $13,375,401$ \\
\hline
\end{tabular}




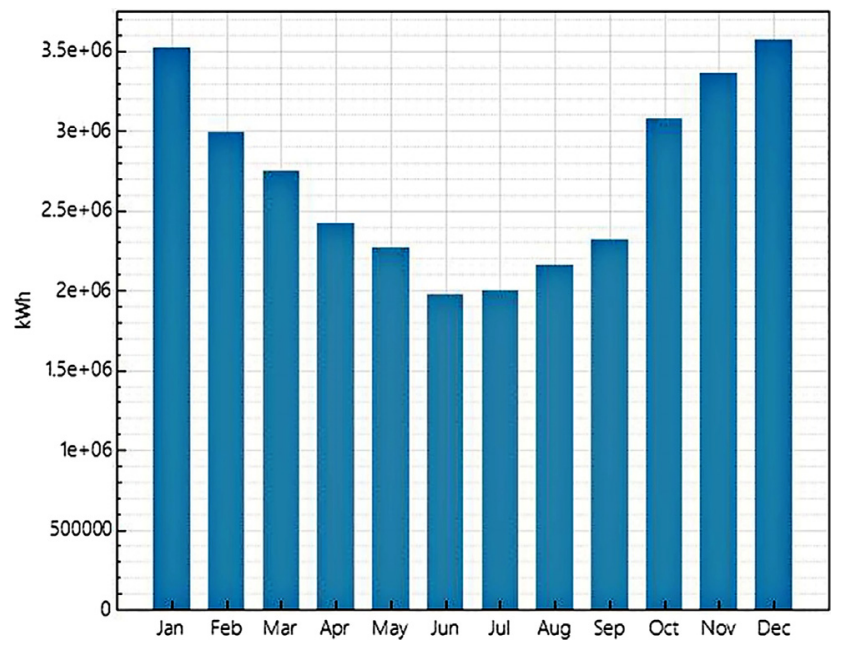

Fig. 6. Monthly energy production for SPP.

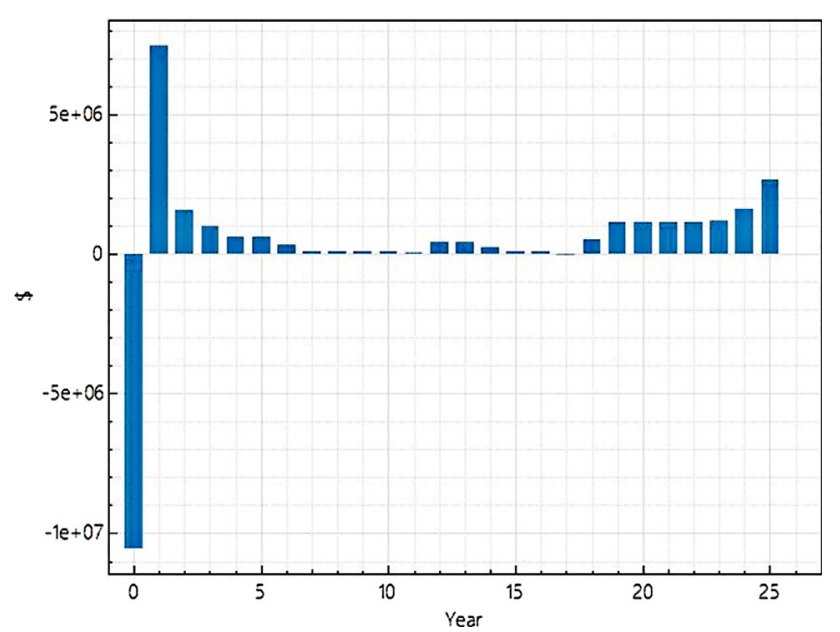

Fig. 7. Project after Tax Cash-flow.

which shares the cost and risks among multiple investors [53]. According to Joyner 2014 [54], there are several types of financial structures for such projects, however, there are fundamentally two sources of capital which are, equity or debt. Characteristically, such infrastructural projects utilize both sources to varying degrees. As a result of the huge cost involve in building nuclear power plants, a government to government financing is usually used in financing such projects and as mentioned earlier, the Russian government is likely to offer financial assistance as they currently doing for countries such as Vietnam, India and Turkey [55]. The build-own-operate and transfer (BOOT) option is also an option that is available to the government of Ghana and other developing countries to consider [56]. This option transfers the financial, operating risks and profits from the government to the private or investing partner, it however needs the government's intervention and support especially in the area of taxation and

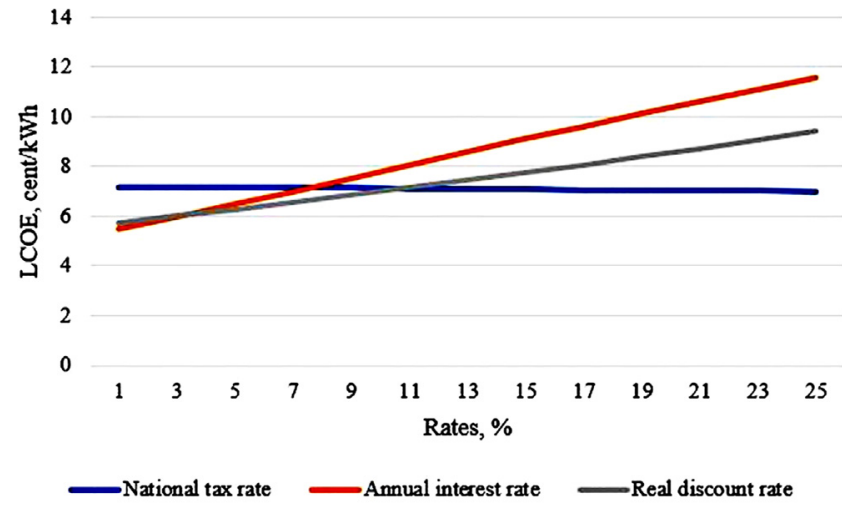

Fig. 8. Sensitivity analysis on the real LCOE for SPP.

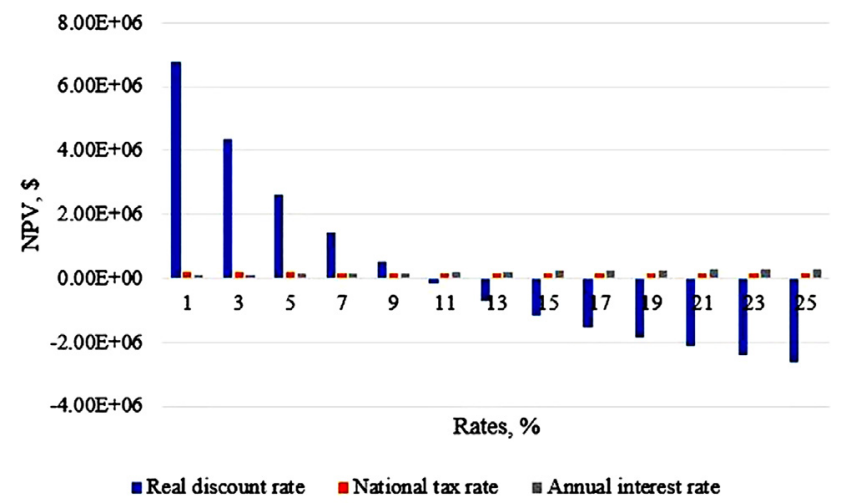

Fig. 9. Sensitivity analysis on NPV after tax with varying real rate for SPP.

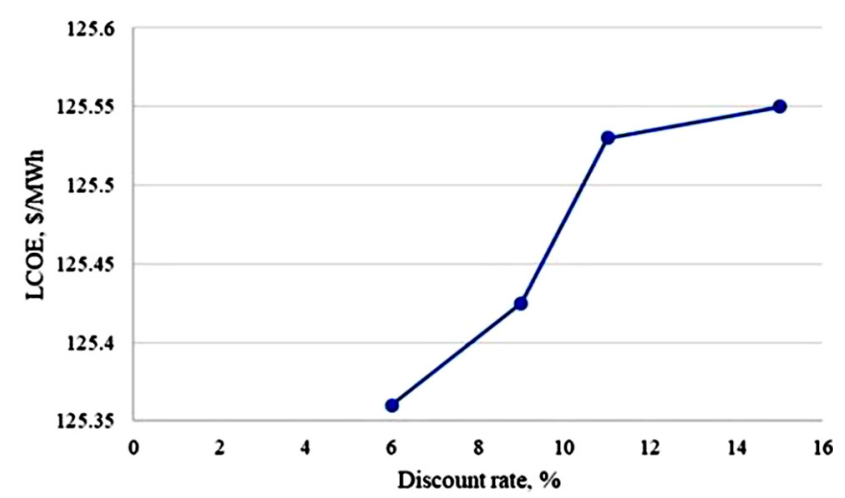

Fig. 10. Sensitivity analysis showing the LCOE for different discount rates for NPP.

regulation. In that situation, the owners will bear non-operational economic risks in case of project termination or delay in construction. The risks are usually spelt out in the contractual agreement between partners. Other financing options may throw the economies of countries who find themselves in the case of Ghana into disarray since borrowing

Table 6

Projected cost of LCOEs of PV power plants by 2020 around the world [50].

\begin{tabular}{lllllll}
\hline Country & $\begin{array}{l}\text { IEA (cent/ } \\
\text { kWh) }\end{array}$ & $\begin{array}{l}\text { Bloomberg New Energy Finance } \\
\text { (cent/kWh) }\end{array}$ & $\begin{array}{l}\text { Europe EPIA (cent euro/ } \\
\mathrm{kWh})\end{array}$ & $\begin{array}{l}\text { Japan NEDO (yen/ } \\
\mathrm{kWh})\end{array}$ & $\begin{array}{l}\text { NERL (cent/ } \\
\mathrm{kWh})\end{array}$ & $\begin{array}{l}\text { China Renewable Energy Committee } \\
\text { (yuan/kWh) }\end{array}$ \\
\hline China & 9 & 7.36 & - & - & - & $0.6-0.8$ \\
Japan & & 11.47 & - & - & - & - \\
India & & 6.83 & - & - & - & - \\
USA & 10 & 7.06 & - & - & - & - \\
Germany & - & 9.36 & 12 & - & 10 \\
\hline
\end{tabular}


Table 7

Summary of renewable energy targets by Ghana's Energy Ministry [17].

\begin{tabular}{lll}
\hline Energy source & $\begin{array}{l}\text { Exploitable potential } \\
\text { (MW) }\end{array}$ & $\begin{array}{l}\text { Investment required US \$ } \\
\text { (Million) }\end{array}$ \\
\hline Wind & 240 & $200-300$ \\
Solar & 50 & $100-150$ \\
Small-Medium hydro & 150 & $200-300$ \\
Modern Biomass & 90 & $90-150$ \\
Total & 500 & $640-900$ \\
\hline
\end{tabular}

Table 8

Current GDP of some African countries and their debt to GDP ratio as at April $2019[58,59]$.

\begin{tabular}{lll}
\hline Country & GDP Prices (billions of \$) & National Debt to GDP Ratio (\%) \\
\hline Nigeria & 444.92 & 30.1 \\
South Africa & 371.30 & 57.8 \\
Egypt & 299.59 & 86.9 \\
Algeria & 183.69 & 46.9 \\
Morocco & 121.35 & 65.1 \\
Kenya & 99.25 & 55.5 \\
Tanzania & 61.03 & 36.6 \\
Ghana & 68.26 & 62.0 \\
Côte d'Ivoire & 45.25 & 50.9 \\
Libya & 44.96 & No data \\
Tunisia & 36.20 & 81.5 \\
Mali & 17.83 & 36.9 \\
Burkina Faso & 14.88 & 42.5 \\
Mauritius & 14.81 & 67.5 \\
Equatorial Guinea & 12.43 & 37.5 \\
Chad & 11.37 & 42.9 \\
Benin & 11.18 & 54.0 \\
Rwanda & 10.21 & 50.0 \\
Niger & 9.72 & 55.6 \\
Malawi & 7.44 & 59.0 \\
Togo & 5.59 & 70.4 \\
Liberia & 3.22 & 46.7 \\
The Gambia & 1.74 & 78.7 \\
Comoros & 0.73 & 35.1 \\
\hline
\end{tabular}

billions of dollars to implement such projects will increase the debt to GDP ratio beyond sustainable levels. According to experts, the huge overnight cost for NPP makes it challenging for developing countries with a GDP below $\$ 50$ billion to commit between 5 and 10 US $\$$ billion for its construction. It is even more challenging with countries with debt to GDP ratio more than $50 \%$ as it can negatively affect the country's cost of finance and credit rating internationally. Fig. 11 is the financing model trend. Table 8 is the current GDP prices of some selected African countries according the International Monetary Fund World Economic Outlook (April 2019).

\section{Standards for Establishment of NPP}

The probability of an NPP accident is low but highly lethal when it happens. In order to avert such accidents, the IAEA has instituted requirements for countries interested in the construction of NPPs to meet before issuing getting the final certification for construction. Construction of an NPP requires a site free from earthquakes hence a special investigation on the geotectonic environment must be conducted with modern engineering equipment to avert any misfortune [60-64]. Factors which can cause nuclear accidents can be classified into two namely: external and internal factors, the external factors include earthquakes, volcanoes, tsunamis and terrorism. Ghana has no history on volcanoes, tsunamis, terrorism and severe earthquakes. The country is located on the southeastern margin in the West African craton which is far away from the main earthquake zones. It has however, experienced some minor earthquakes recently ranging between 1.0 and 4.8 on the Richter scale [65]. For the internal factors,
NPPs are designed with high quality construction equipment that can avert operational instabilities. It operates using a defense-in-depth approach to prevent any accident that maybe caused as a result of internal defects. Siting of NPPs also requires a stable political environment not only in the country but also in neighboring countries since any destabilization in the neighboring countries could affect Ghana as a result of its porous borders.

According to the IAEA, for a country to safely and successfully integrate nuclear power into its generation mix, that country must have a grid system that is approximately ten times the capacity of the intended nuclear power plant to be constructed [66]. However, Ghana's total installed capacity according to the Energy Commission's 2018 report [12], stands at about 4,310 MW. This is woefully inadequate for the intended 1000-1200 MW NPP the country seeks to add to the generation mix.

The possible effect of these technologies on Ghana's economic development

Ghana's current energy crisis can be associated with the lack of fuel to run the currently installed thermal power plants as a result of the huge energy sector debt. According to Ghana's Minister for Finance, Mr. Ken Ofori Atta "Energy sector debt is a risk to the economy" he therefore professed a state of emergency in the energy sector, which is symptomatic of the challenges in the sector. The Minister linked the cause of the challenge to the take-or-pay contract signed by the erstwhile government [67]. The Energy Commission's 2018 report was of the view that, the country needed close to US $\$ 905$ million to pay for fuel alone to run its thermal power plants, without which the country would have been plunged into power crisis. As a result of the nexus between economic development and access to electrical power, the country lost huge sums of money during the energy crisis which had a negative effect on the country. According to the World Bank, Ghana lost about $1.8 \%$ of its GDP in the 2007 electricity crisis. Research also indicates that, the country lost about US $\$ 2.1$ million each day equivalent to US $\$ 670.8$ million in a year in the 2014 national power crisis representing $2 \%$ of GDP [68].

The short- and medium-term effect of power is key to the growth of an economy, this brings into the discussion the timelines for the construction of both technologies. As indicated in Table 4, construction of an NPP can take as much as 12 years to be operational this is without the long period needed for preparation and licensing, it therefore brings into question the ability of developing economies to integrate this technology before the 2030 deadline for the Sustainable Development Goal 7.

Whereas the construction of NPPs takes a longtime to complete, construction of SPPs even those with capacities greater than $10 \mathrm{MW}$ can be completed in few months. Research indicates that an SPP with capacities between 1 and 5 MW can be constructed within 4-5 months. This includes the following stages [69]:

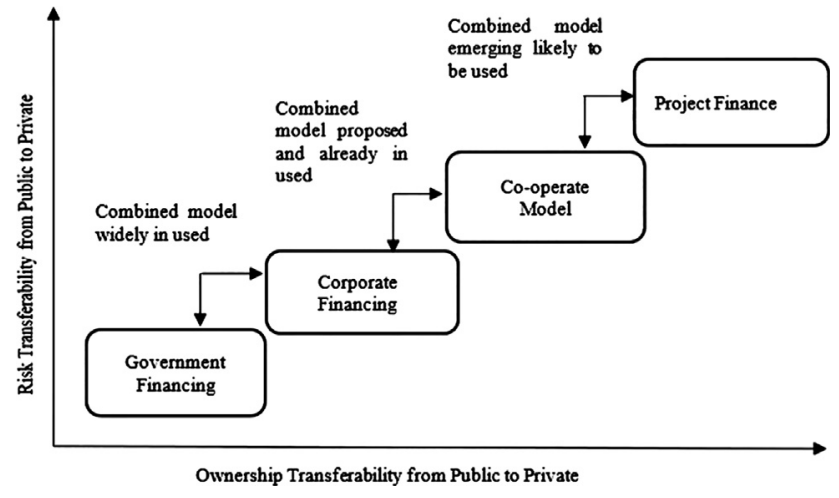

Fig. 11. Emerging trends of financing models for NPPs [57]. 
- Planning and development - consisting of surveys, initial design, developing the approach for the site as well as securing the required approvals.

- System design - this includes shadow analysis as well as deciding on the optimal placing for the modules, design and layout of the whole power plant, for both alternating current and direct current sides of the SPP, and the design for the power transmission to the sub-station.

- Procurement of Components - this consists of the procurement of all necessary components for the power plant such as inverters and solar panels as well as the balance of systems.

- Construction - it includes the main civil engineering, installation of the SPP system, installation of the evacuation system and testing of the system.

The timelines for the construction of these power plants are critical to the economic development of a country in economic transition, developing economies such as Ghana are confronted with electrical power deficit which has slowed development. It is therefore critical for the developing countries to develop short, medium and long-term development plan for the energy sector. Availability of cheap, clean and sustainable energy is key to the realization of most of the sustainable development goals set up by the United Nations in 2015. Most African countries cannot achieve this target by the said deadline if a comprehensive energy plan is not drawn. The timelines needed for the construction of an NPP clearly puts it out of the 2030 deadline, it is therefore needed to explore the continent's renewable energy options such as solar energy whose construction can be achieved in few months to help realize the 2030 deadline.

\section{Countermeasures and recommendations for the development of both energies in Africa}

Strong policies drive investments into countries, it is therefore important that nations that seek to invest in both renewable and nuclear power plants, reform their policies to enable competition in the energy sector. Investors do not finance projects in countries with high risks. The following suggestions are proposed to both decision and policy makers to help develop the energy sector:

- Creation of deliberate policies - it is necessary for countries that intend to integrate nuclear and renewable energy technologies into their generation mix to design electricity markets that puts premium on clean energy. The high initial capital required for these projects necessitates strong policy interventions to protect investments, Ghana and other developing countries need to direct their attention towards the removal of measures that serve as barriers to investments. Policy instruments such as reduction in taxes, feed-in-tariffs and clean energy portfolio should be applied to such technologies. It is also important to create a framework that manages risks in the sector to assure the investor community of a secured investment.

- Support for new projects - delays in construction period for such projects increases cost, it is therefore incumbent on governments to reduce the bureaucratic processes needed for documentations and licensing of these projects whiles still maintaining safety measures.

- Minimization of corruption - Corruption is a major hinderance to development, and most developing countries on the continent are faced with this canker. Corruption is a threat to the peaceful use of nuclear power; it is a key factor to nuclear proliferation even though it is under-recognized. Managers of the nuclear facility if compromised could handover sensitive (fissile) materials to outsiders which can affect safety. It could also affect the capital cost of the project and delays which will affect the cost of energy generation at the end of the project.

- Promotion of hybrid system - operating a hybrid system in the renewable energy sector is an opportunity to compensate for intermittency in the energy generation system through the use of other energy generating sources, this could be a combination of renewable - renewable or renewable - nonrenewable sources. Research shows that, hybrid power plants in Nigeria could produce electricity at lower rates than that solely generated from diesel generators [70]. This is important because from the modelled results in Fig. 6, energy production falls between the months of May and September as a result of low solar radiation within the period, hence the need for a hybrid system to provide the shortfall.

- Increased transparency - investor confidence can be derailed if there is uncertainty in policy direction and implementation. For example, frequent policy-reversals as well as irregularities in implementation can cast doubt on a government's readiness and ability to transition towards clean energy [71]. It is therefore important for countries to develop a consistent energy policy which can withstand political regime change. Most investors fail to invest in African countries partly because of fear of discontinuity in policy during political regime change.

\section{Limitations of this research}

It is instructive to note that, this current work only considered the economics and funding capabilities of African countries relative to the development of both projects. It does not comprehensively access the level of public acceptance or rejection for both technologies. There are other factors such as security, safety issues and technical capacity particularly in the case of nuclear energy which may also be studied in future works.

\section{Conclusion}

This work looks at two possible energy sources for developing countries with a case study on the Republic of Ghana, that is nuclear and solar energy. The techno-economic assessment of both technologies was done using the LCOE metric. From the analysis, the LCOE obtained from the $20 \mathrm{MW}$ solar power plant modelled ranges between 5 and 12 $\$ / \mathrm{kWh}$ depending on the real discount, national tax and annual interest rates. The LCOE for a 1200 MW Russian VVER module ranges between 125.53 and 125.55 \$/MWh for discount rates between $3 \%$ and $15 \%$, which indicates that, the discount rate has a relatively insignificant effect on the LCOE of the NPP. However, there are several factors such as O\&M and cost of land among other key factors that may affect the LCOE which were not considered in this paper. The greater part of the obtained LCOE's for both technologies appears in regions less than the current end user tariff for the energy generated from thermal power generators which ranges between 15 and $19 \$ / \mathrm{kWh}$. The research can therefore suggest that both technologies are possible but the question is economic capacity of developing countries to fund such huge projects. In the case of the NPP, it is clear that even though Ghana's GDP is a little over $\$ 68$ billion dollars, its dept to GDP ratio has been projected to hit $62 \%$ by close of 2019 . This makes it difficult for the government to invest in a single project worth about $6-10 \%$ of the country's GDP, it is not only peculiar to Ghana but also to majority of African countries. The government of Ghana and other several countries who fall into the same category may consider a joint venture agreement for the development of such technologies. They may also consider Private Financing model which ranges from corporate to project financing. Even though, nuclear power is a clean energy option for Ghana and other developing countries, its cost will have to be reduced significantly in order to compel investment particularly in developing economies.

However, SPP have a relatively lower construction cost, the Ministry of Energy for Ghana has budgeted to construct a 50 MW SPP at a cost which ranges between $\$ 100-\$ 150$ million, on the face value, the $\$ 7$ billion needed for 1200 MW NPP is capable of constructing about $2333 \mathrm{MW}$ power from SPP. In as much as both technologies are viable, this paper recommends to governments of developing countries 
particular in Africa to invest more in the construction of SPPs in the short to medium term to help transform their respective economies since the availability of clean and cheap energy have a direct nexus with economic transformation and development. Appropriate framework and policies should be enacted to create a conducive financial environment to promote investment in SPP from the private sector. Consideration for an NPP in developing countries can be done after a robust economy is built in the long-term.

\section{Funding}

NA

\section{Author contribution}

Ephraim Bonah Agyekum conceptualized and wrote the final manuscript, Velkin Vladimir Ivanovich supervised the work and Ismail Hossain writing- reviewed the work.

\section{Declaration of Competing Interest}

The authors declare that they have no known competing financial interests or personal relationships that could have appeared to influence the work reported in this paper.

\section{References}

[1] Agyekum EB, Velkin VI, Hossain I. Comparative evaluation of renewable energy scenario in Ghana. In: IOP conference series: materials science and engineering 2019 Nov (Vol. 643, No. 1, p. 012157). IOP Publishing. doi:10.1088/1757-899X/ 643/1/012157.

[2] Wang C, Zeng K. A survey of nuclear and solar energy. In: Advanced materials research 2012 (Vol. 535, pp. 2116-9). Trans Tech Publications.

[3] Klessmann C, Held A, Rathmann M, Ragwitz M. Status and perspectives of renewable energy policy and deployment in the European Union-What is needed to reach the 2020 targets? Energy Policy 2011 Dec 1;39(12):7637-57.

[4] Sah A, Lovering J, Maseli O, Saxena A. Atoms for Africa: is there a future for civil nuclear energy in Sub-Saharan Africa? Center for Global Development; 2018 Apr. https://www.cgdev.org/publication/atoms-africa-there-future-civilnuclear-energysub-saharan-africa.

[5] Ramana MV, Agyapong P. Thinking big? Ghana, small reactors, and nuclear power. Energy Res Social Sci 2016 Nov;1(21):101-13.

[6] Asante AF. Ghana's Electricity Industry; 2007. https://www.esi-africa.com/ghana-selectricity-industry/ Accessed 24 January, 2019.

[7] Danso-Wiredu EY, Dadson YI, Amoako-Andoh FO. Social, economic and environmental impacts of the recent electricity crisis in Ghana: a study of winneba. J. Social Sci. 2016 Dec 1;49(3-1):277-88.

[8] Marktanner M, Salman L. Economic and geopolitical dimensions of renewable vs. nuclear energy in North Africa. Energy Policy 2011;39:4479-89.

[9] Medium Term. Expenditure framework (MTEF) for 2018-2021. Ministry of Energy, Accra; 2018.

[10] Ahiataku-Togobo W. Perspectives on renewable energy investment in Ghana, In: Seminar on sustainable energy investment in Africa, UN City 2014, Copenhagen.

[11] Guest Contributor, Ghana's Largest Solar PV Project Just Connected to The Grid, Cleantech. http://cleantechnica.com/2016/04/17/ghanas-largest-solar-pv-projectjust-connected-to-the-grid/, 2016 Accessed 25 January 2019.

[12] Energy Commission of Ghana Report; 2018. http://www.energycom.gov.gh/ planning/data-center/energy-outlook-for-ghana Accra Accessed 25 January, 2019.

[13] Presidential Committee on Nuclear Power Study Report; December 2008.

[14] Country Nuclear Power Profiles 2018 Edition, IAEA, https://www-pub.iaea.org/ MTCD/Publications/PDF/cnpp2018/countryprofiles/Ghana/Ghana.htm Accessed 26 January, 2019.

[15] Gyamfi S, Modjinou M, Djordjevic S. Improving electricity supply security in Ghana-the potential of renewable energy. Renew Sustain Energy Rev 2015 Mar;1(43):1035-45.

[16] Eshun ME, Amoako-Tuffour. A review of the trends in Ghana's power sector. Energy Sustain Soc 2016;6:9.

[17] Gauri S, Alzouma S, Sokuona MY. Ghana renewables readiness assessment, IRENA; 2015 [chapter 2]. p. 16-7

[18] Solar and Wind Energy Assessment (SWERA) Ghana http://www.energycom.gov. gh/downloads/Technical\%20Reports/SWERA\%20-\%20National\%20Report.pdf Accessed 29 January, 2019.

[19] DLR. Solar and wind energy resource assessment (SWERA).DLR-activities within SWERA2004.

[20] System Advisor Model (SAM), https://sam.nrel.gov/ Accessed 16 September, 2019.

[21] Upper East Region, http://mofa.gov.gh/site/?page_id=654 Accessed 16 September, 2019.
[22] Hernández-Moro J, Martínez-Duart JM. CSP electricity cost evolution and grid parities based on the IEA roadmaps. Energy Policy 2012;41:184-92. https://doi. org/10.1016/j.enpol.2011.10.032.

[23] Aly A, et al. Is Concentrated Solar Power (CSP) a feasible option for Sub-Saharan Africa?: investigating the techno-economic feasibility of CSP in Tanzania. Renew Energy 2019 May;1(135):1224-40.

[24] United States Inflation Rate. https://tradingeconomics.com/united-states/inflationcpi Accessed 27 April, 2019.

[25] Hernández-Moro J, Martínez-Duart JM. Analytical model for solar PV and CSP electricity costs: Present LCOE values and their future evolution. Renew Sustain Energy Rev 2013;20:119-32.

[26] Adaramola MS, et al. Multipurpose renewable energy resources based hybrid energy system for remote community in northern Ghana. Sustain Energy Technol Assess 2017;22:161-70.

[27] Ghana Sales Tax. https://tradingeconomics.com/ghana/sales-tax-rate, Accessed 28 March, 2019.

[28] Simple Tax Guide for Americans in Ghana. https://www.taxesforexpats.com/ ghana/us-tax-preparation-in-ghana.html Accessed on 28 March 2019.

[29] Insuring Solar Photovoltaics: Challenges and Possible Solutions. https://www.nrel. gov/docs/fy10osti/46932.pdf Accessed 18 November, 2019.

[30] Mathew Mobi, et al. Outdoor measurement of mono and poly c-Si PV modules and array characteristics under varying load in hot-humid tropical climate. Mater Today: Proc 2018;5:3456-64.

[31] Jordan DC, Kurtz SR. Photovoltaic degradation rates-an analytical review. Prog Photovoltaics Res Appl 2013 Jan;21(1):12-29.

[32] Ghana's nuclear power agenda on course - Phase II of project scheduled for Q1 2019. https://gaecgh.org/ghanas-nuclear-power-agenda-on-course-phase-ii-ofproject-scheduled-for-q1-2019/ Accessed 28 April, 2019.

[33] Kazimiet M. et al. The future of the Nuclear fuel cycle. Massachusetts Institute of Technology, 2011.

[34] Wang K. Nuclear power economic costs. Stanford University; 2018.

[35] Adamantiades A, Kessides I. Nuclear power for sustainable development: current status and future prospects. Energy Policy 2009 Dec 1;37(12):5149-66.

[36] Matsuo Y, Nei H. An analysis of the historical trends in nuclear power plant construction costs: The Japanese experience. Energy Policy 2019 Jan;1(124):180-98.

[37] Schlissel D, Biewald B. Nuclear power plant construction costs, Synapse Energy Economics, Inc; 2008. http://www.synapse-energy.com/sites/default/files/ SynapsePaper.2008-07.0.Nuclear-Plant-Construction-Costs.A0022_0.pdf Accessed 30 April, 2019.

[38] VAT in Ghana. https://gra.gov.gh/index.php/charging-vat/ Accessed 23 April, 2019.

[39] Xoubi N. Economic assessment of nuclear electricity from VVER-1000 reactor deployment in a developing country. Energy 2019;175:14-22.

[40] Karaveli AB, Soytas U, Akinoglu BG. Comparison of large-scale solar PV (photovoltaic) and nuclear power plant investments in an emerging market. Energy 2015 May;1(84):656-65.

[41] The rising cost of decommissioning a nuclear power plant. https://thebulletin.org/ 2014/04/the-rising-cost-of-decommissioning-a-nuclear-power-plant/ Accessed 30 April, 2019.

[42] International Energy Agency. OECD Nuclear Energy Agency. Nuclear new build: insights into financing and project management. 2015. https://www.oecd-nea.org/ ndd/pubs/2015/7195-nn-build-2015.pdf.

[43] IAEA. Power Reactor Information System (PRIS) Database. http://www.iaea.org/ programmes/a2/, Accessed 12 May, 2019.

[44] Lazard's levelized cost of energy analysis - version 11.0. https://www.lazard.com/ media/450337/lazard-levelized-cost-of-energy-version-110.pdf Accessed 27 May, 2019.

[45] Breeze P. The cost of electricity from nuclear power stations. Nucl Power 2017:95-9. https://doi.org/10.1016/B978-0-08-101043-3.00010-9.

[46] Country Nuclear Power Profiles. https://cnpp.iaea.org/countryprofiles/Russia/ Russia.htm Accessed 30 September, 2019.

[47] EIA. Annual Energy Outlook 2018, Technical report, U.S. Department of Energy, Energy information agency; 2018.

[48] Comello S, Reichelstein S, Sahoo A. The road ahead for solar PV power. Renew Sustain Energy Rev 2018 Sep;1(92):744-56.

[49] DOE Officially Marks SunShot's $\$ 1$ per Watt Goal for Utility-Scale Solar, https:// www.greentechmedia.com/articles/read/doe-officially-hits-sunshot-1-per-wattgoal-for-utility-scale-solar\#gs.Ff41PZ7U September 2017. Accessed on 28 May, 2019.

[50] Zhao L, Wang W, Zhu L, Liu Y, Dubios A. Economic analysis of solar energy development in North Africa. Glob Energy Interconnection 2018 Jan 1;1(1):53-62.

[51] Schneider M, Froggatt A. The world nuclear industry status report 2015.

[52] Ghana Government Debt to GDP. 2019. https://tradingeconomics.com/ghana/ government-debt-to-gdp Accessed 10 March, 2019.

[53] Terlikowski P, et al. Modern financial models of nuclear power plants. Prog Nucl Energy 2019 Jan;1(110):30-3.

[54] Joyner DH. Nuclear power plant financing post-fukushima, and international investment law. J World Energy Law Bus 2014;7:(2).

[55] Ahmad A. Economic risks of Jordan's nuclear program. Energy Sustain Develop 2015 Dec;1(29):32-7.

[56] Nyarko BJ, Akaho EH, Ennison I. Nuclear power for future electricity generation in Ghana: Issues and challenges. 2009. https://www-pub.iaea.org/MTCD/ publications/PDF/P1500_CD_Web/htm/pdf/topic2/2S03_B.J.B.\%20Nyarko.pdf.

[57] Barkatullah N, Ahmad A. Current status and emerging trends in financing nuclear power projects. Energy Strategy Rev 2017 Dec;1(18):127-40.

[58] GDP: https://www.imf.org/external/datamapper/NGDPD@WEO/OEMDC/ 
ADVEC/WEOWORLD Accessed 22 June, 2019

[59] General government gross debt Percent of GDP. https://www.imf.org/external/ datamapper/GGXWDG_NGDP@WEO/OEMDC/ADVEC/WEOWORLD Accessed 28 June 2019.

[60] Hossain I, Akbar MS, Velkin VI, Shcheklein SE. Seismic safety evaluation during site selection for the nuclear power plants in Bangladesh. Nucl Energy Technol 2018;4(4):251-6. https://doi.org/10.3897/nucet.4.31873.

[61] Agyekum EB, Daneykin Y. Modelling of gamma-scan detector with collimator to investigate differential radioactive contamination. Global Nucl Safety MEPhI 2018;2(27):C.66-73.

[62] Velkin VI, Shcheklein SE, Ismail H, Nikitin A, Chikansev G. Investigation of the effect of passive vortex inserts of different geometrical shapes on the vibrations reduction efficiency in pipelines with two-phase flow. In: MATEC web of conferences 2017 (Vol. 115, p. 05012). EDP Sciences. doi.org/10.1051/matecconf/ 201711505012.

[63] Hossain I, Velkin VI, Shcheklein SE. The study of passive vibration dampers in pipelines using PIV-methodology for single phase flow. WIT Trans Ecol Environ 2017 Dec;7(224):565-70. https://doi.org/10.2495/ESUS170521.

[64] Hossain I, Velkin VI, Shcheklein SE. Experimental study in reduction of two phase flow induced vibration. In MATEC web of conferences 2018 (Vol. 211, p. 16001).
EDP Sciences. doi.org/10.1051/matecconf/201821116001

[65] Amponsah PE. Seismic activity in Ghana: past, present and future. Ann Geophys 2004 Dec;25(47):2-3.

[66] Agyekum EB, et al. Nuclear energy for sustainable development: SWOT analysis on Ghana's nuclear agenda. Energy Rep 2020;;6:107-15. https://doi.org/10.1016/j. egyr.2019.11.163.

[67] Ghana Fin Min: Energy sector debt a risk to economy. https://www.cnbcafrica. com/videos/2019/07/31/ghana-finmin-energy-sector-debt-a-risk-to-economy/ Accessed 6 October 2019.

[68] Kumi EN. The electricity situation in Ghana: challenges and opportunities. Washington, DC: Center for Global Development; 2017 Sep.

[69] Timelines of a MW Solar Project Installation in India Read more at: http://www. solarmango.com/2015/12/14/timelines-of-a-mw-solar-project-installation-inindia/ Accessed 7 October, 2019.

[70] Adaramola MS, et al. Assessment of decentralized hybrid PV solar-diesel power system for applications in Northern part of Nigeria. Energy Sustain Dev 2014;19:72-82.

[71] Steckel JC, Jakob M. The role of financing cost and de-risking strategies for clean energy investment. Int Econ 2018;155:19-28. 